\title{
RELAÇÃO MÚTUA ENTRE ELEMENTOS DA CRIATIVIDADE E COMPETÊNCIA EM INFORMAÇÃO
}

\author{
Gabriela Belmont de Farias*
}

RESUMO $\bigcirc$ artigo apresenta, por meio de levantamento bibliográfico e observação sistemática, uma reflexão sobre os aspectos teóricos que abrangem os conceitos relacionados ao fenômeno da criatividade e sua inter-relação com o desenvolvimento da competência em informação (Colnfo). Destaca as relações estabelecidas entre os modelos teóricos cognitivismo sobre a criatividade de Teresa Amabile (Modelo Componencial da Criatividade, de Mihaly Csikszentmihalyi (Perspectiva de Sistemas) e de Robert Sternberg (Teoria do Investimento em Criatividade) e os padrões e indicadores da Information Literacy Competency Standards for Higher Education da Association of College and Research Libraries (ACRL, 2000). Observou-se que os modelos teóricos da criatividade analisados, são considerados padrões de abordagens confluentes, pois visam ao estudo da criatividade como um fenômeno complexo multifacetado, sujeito a influências ambientais ou motivacionais. São elementos fundamentais e inter-relacionados com os padrões e indicadores da Competência em Informação. As inter-relações estabelecidas e apresentadas tornam-se subsídios para uma prática sustentável com base no desenvolvimento de indivíduos socialmente responsáveis e conscientes de sua atitude perante as demandas da sociedade.

\footnotetext{
* Doutora em Ciência da Informação pela Universidade Estadual Paulista Júlio de Mesquita Filho, Brasil. Docente permanente no Programa de Pós-Graduação em Ciência da Informação da Universidade Estadual Paulista Júlio de Mesquita Filho, Brasil.

E-mail: gabriela_belmont@yahoo.com.br.
}

Palavras-Chave:Criatividade. Competência em Informação.

\section{INTRODUÇÃO}

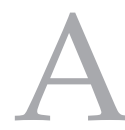

sociedade vislumbra o progresso de inovação e renovação a cada instante, exigindo dos indivíduos mais dinamismo e ações criativas ligadas às necessidades que a permeiam. Ante essa constatação, pressupõese que não basta instruir o que é conhecido, havendo que se fomentar nos indivíduos a capacidade de questionar, refletir, agir e criar soluções viáveis e inovadoras.

$\mathrm{O}$ termo criatividade tem como ponto em comum, em suas definições, o ato de criar um produto, "[...] seja uma ideia ou invenção original, seja a reelaboração e aperfeiçoamento de produtos ou ideias já existentes" (ALENCAR, 1986, p.12).

A criatividade encena uma nova concepção, sob a qual a pessoa passa por um desenvolvimento e por um aprimoramento de suas habilidades criativas mediante as práticas e a formação. A criação deixa de ser uma inspiração e se torna habilidade que pode ser adquirida por meio da preparação da pessoa, a qual, Alencar (1986), entende que para alcançar o produto criativo são necessários pré-requisitos, como disciplina, dedicação, esforço consciente, trabalho prolongado e conhecimento amplo de uma área do saber.

Em síntese, pode-se afirmar que a criatividade surge do esforço, trabalho e 
dedicação prolongada, como também de certos traços de personalidade e características cognitivas. É necessário destacar que o processo criativo é complexo e multidimensional. A cognição está relacionada a ordem psicológica que envolve os atos de conhecer, compreender, perceber e aprender, entre outros. A cognição está relacionada ao modo de como a pessoa vê e percebe, de que maneira registra as informações e o modo como acrescenta as novas informações ao conhecimento previamente registrado.

Como explica Alencar (1986), os fatores cognitivos e os de personalidades se relacionam intimamente, ou seja, o que ocorre na área cognitiva afeta diretamente a personalidade e vice-versa. A criatividade, como qualquer traço ou característica humana, necessita de condições adequadas para que possa desenvolverse. "A criatividade é função tanto de fatores intrapessoais como de fatores interpessoais, tanto de fatores internos como de fatores sociais" (ALENCAR, 1986, p.39).

A título de melhor elucidação, destacase o fato de que as investigações acerca da criatividade na Psicologia são divididas em quatro grandes períodos, conforme detalha Pereira (1996) o primeiro configura-se com a aproximação da criatividade com o tema sobredotação e, dessa forma, era estudado como sendo atributo de alguns privilegiados; o segundo período é marcado pela declaração de Guilforde, presidente da American Psychological Association (APA), em 1950, na conferência intitulada 'Creativity', que enfatizou a escassez de estudos sobre criatividade. Desde então, houve um desencadeamento nas pesquisas, em que a temática da criatividade passou a despertar a atenção, não só de investigadores da Psicologia, mas também da Filosofia, Matemática, Pedagogia, Engenharia e Sociologia. (SANTOS, 2010). O interesse pelo estudo da criatividade emerge da complexidade humana e do alcance em âmbito socioeconômico, nas Artes, nas Tecnologias e nas Ciências, além de outros ambientes da sociedade.

A criatividade, no período de 1950 a 1960, passou a ser analisada como variável contínua, que pode ser estimulada ou inibida. As áreas de investigação, neste período, se concentram na clarificação das relações entre criatividade e inteligência; o desenvolvimento e validação de instrumentos de avaliação da criatividade surgiu nos programas de desenvolvimento de competências criativas. São também alvo de estudos as características da personalidade do sujeito criativo. O terceiro período ocorreu nos Anos de 1970 a 1980 com a ideia e a proliferação de programas de promoção da criatividade.

$\mathrm{O}$ quarto e último período inicia-se em 1990 e, de acordo com Pereira (1996), esse novo ciclo é denominado 'ecologia views'. Marcam este período as modificações que ocorreram nas concepções de inteligência e sobre dotação. "A criatividade começa a ser compreendida à luz de modelos interativos em detrimento das abordagens psicométricas tradicionais." (SANTOS, 2010, p.27).

O artigo apresenta, por meio de levantamento bibliográfico e observação sistemática, uma reflexão sobre os aspectos teóricos que abrangem os conceitos relacionados o fenômeno da criatividade e sua inter-relação para o desenvolvimento da competência em informação (CoInfo). Destaca as relações estabelecidas entre os modelos teóricos cognitivismo sobre a criatividade e os padrões e indicadores da Information Literacy Competency Standards for Higher Education da Association of College and Research Libraries (ACRL, 2000).

Antes de se adentrar a reflexão sobre os modelos teóricos da criatividade, convém lembrar que existem várias perspectivas relacionadas ao estudo da criatividade. Assim, a perspectiva psicanalítica associa a criatividade à imaginação, referindo-se à criatividade como resultado de um conflito no inconsciente apenas produzido por pessoas insatisfeitas. A perspectiva humanista associa a criatividade à capacidade de a pessoa se desenvolver e se realizar num projeto singular. Por outro lado, para a perspectiva fatorialista, o pensamento criativo é traduzido em dimensões intelectuais estáveis, mas, na perspectiva associacionista, a criatividade é um processo de associações novas de informações preexistentes (SANTOS, 2010).

Para a perspectiva da Gestalt, a criatividade está associada à solução de um problema ou na possibilidade de reestruturação da informação. Por sua vez, sob o prisma cognitivista, o desenvolvimento do pensamento criativo é possível por meio de estratégias específicas, como: tempestade de ideias e soluções de problemas. Ressalte-se, no entanto, que existem, ainda, outras perspectivas, possíveis 
de encontrar na literatura especializada, que não constituem objeto de atenção deste artigo, por esse motivo, não serão aqui abordadas.

É importante destacar, também, o fato de que a criatividade está relacionada com a utilização de modelos, mecanismos e métodos que não respondem a esquemas e lógicas tradicionais. Mente criativa é aquela que procura métodos diferentes e que é capaz de reinterpretar a realidade segundo novos parâmetros lógicos; tudo com a finalidade de encontrar formas de interpretar a realidade e de dar respostas criativas e eficazes aos problemas que possam surgir.

A criatividade é complexa e ambígua. Por esse motivo, sua gestão deve ser feita com modelos e técnicas que ofereçam a liberdade necessária para o seu desenvolvimento, sendo que os principais modelos foram identificados na literatura especializada e são descritos na sequência.

\section{MODELOS TEÓRICOS SOBRE CRIATIVIDADE}

O desenvolvimento da criatividade só é possível com a combinação de vários fatores, entre eles, o cognitivismo, os elementos de personalidade e o contexto onde a pessoa se insere. Existem modelos teóricos sobre a criatividade: de Teresa Amabile - modelo componencial da criatividade; Mihaly Csikszentmihalyi - perspectiva de sistemas; e Robert Sternberg - teoria do investimento em criatividade. São considerados modelos de abordagens confluentes, pois visam ao estudo da criatividade como procedimento complexo, multifacetado, sujeito a influências ambientais ou motivacionais.

O modelo componencial da criatividade de Amabile (1983-1996) supõe, desde logo, que o produto ou resposta criativa é um elemento apropriado, útil e de valor para o problema em questão e que a tarefa é heurística e não algorítmica. A criatividade, para essa autora, está relacionada a aspectos como originalidade e adequação da resposta, bem como a necessidade e a tarefa proposta possibilitarem vários caminhos para a solução do problema. Seu modelo (Figura 1) procura elucidar a influência de variáveis cognitivas, sociais, motivacionais e de personalidade no processo criativo, cujo a habilidade de domínio, processos criativos relevantes e motivação intrínseca são traços predominantes. Para que a criatividade ocorra, porém, é necessário que os três elementos estejam em interação.

Figura 1: Componentes do Modelo Componencial da Criatividade.

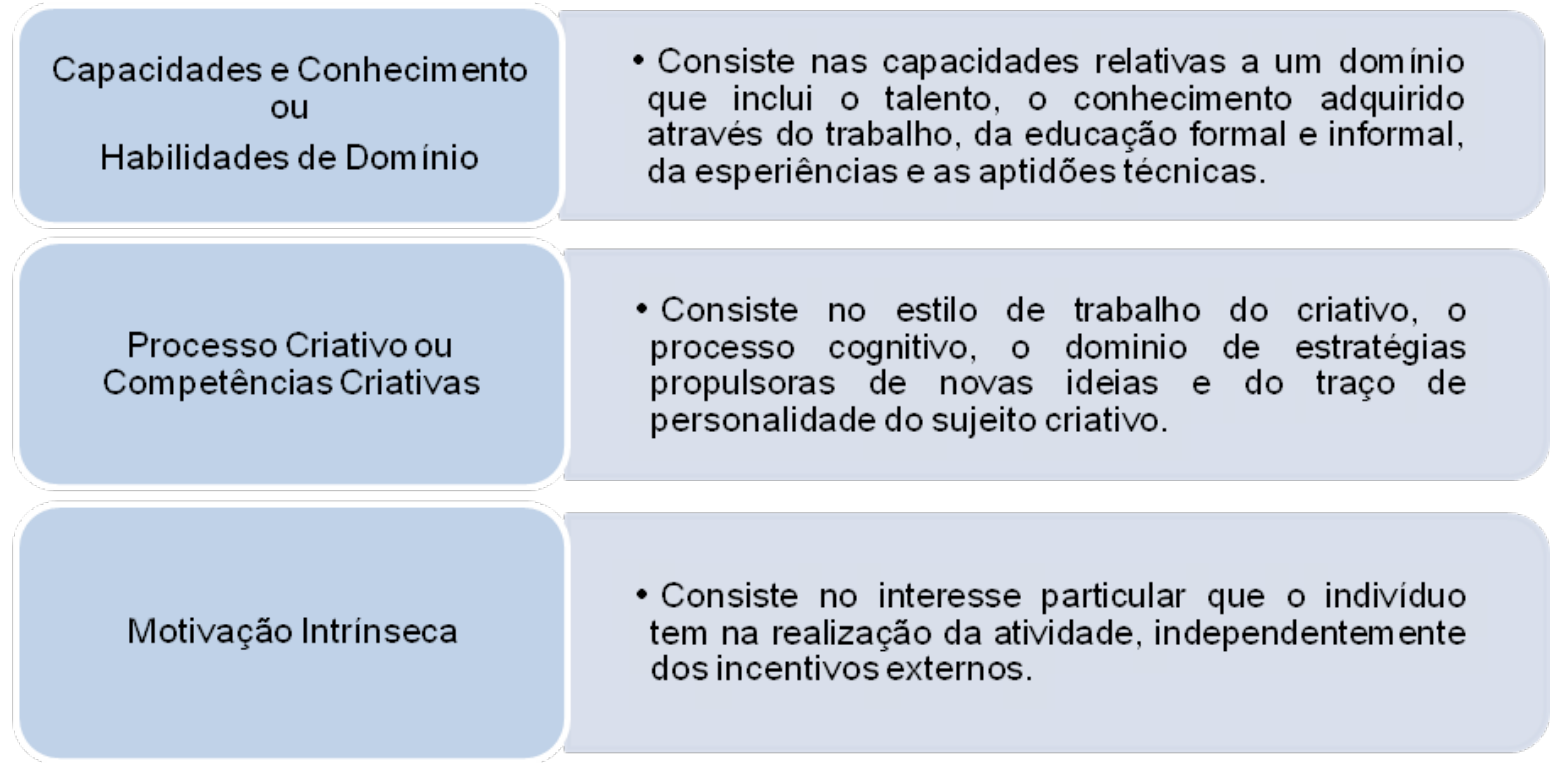

Fonte: Adaptado de Amabile, (1989). 
Verifica-se que o primeiro elemento inclui vários componentes relacionados ao nível de expertise em um domínio, sendo que alguns desses elementos podem ser considerados inatos e que a educação e experiência contribuem também para o seu desenvolvimento.

Para Alencar e Fleith (2003, p.4) “[...] as contribuições criativas não ocorrem no vácuo, mas estão alicerçadas em um amplo conhecimento da área em que se está atuando." O segundo elemento do modelo tem componentes que influenciam no uso que se faz das habilidades de domínio. De acordo com Amabile (1989), o estilo de trabalho criativo é caracterizado como habilidade de se concentrar por longos períodos, dedicação ao trabalho, alto nível de energia, persistência perante a dificuldade, busca da excelência e habilidade de abandonar ideias improdutivas.

O estilo cognitivo está relacionado aos aspectos de quebra de padrões usuais de pensamento e de hábitos; compreensão de complexidades; produção de várias opções; suspensão de julgamento no momento de geração de ideias; flexibilidade perceptual; transferência de conteúdo de um contexto para outro e armazenamento e recuperação de ideias. O domínio de estratégias está alicerçado em princípios heurísticos como: torne o familiar estranho; gere hipóteses; use analogias, investigue incidentes paradoxais e brinque com as ideias. Os traços de personalidade, como a autodisciplina, persistência, independência, tolerância por ambiguidade, o não conformismo, automotivação e desejo de correr riscos podem contribuir para o desenvolvimento dos processos criativos relevantes.

O terceiro e último elemento do modelo refere-se à motivação intrínseca. Embora seja considerada inata, ela pode ser cultivada, em larga escala, pelo ambiente social. A motivação intrínseca pode dificultar, em parte, o processo criativo, entretanto, existem dois tipos de motivação extrínseca, sendo que uma pode levar a pessoa a se sentir controlada e o outro tipo prover informações que contribuam para que a pessoa complete a atividade com sucesso.

O modelo de criatividade proposto por Amabile (1989) prevê cinco fases no desenvolvimento da criatividade, (Figura 2).

Figura 2: Fases no desenvolvimento da criatividade.

Fase 1

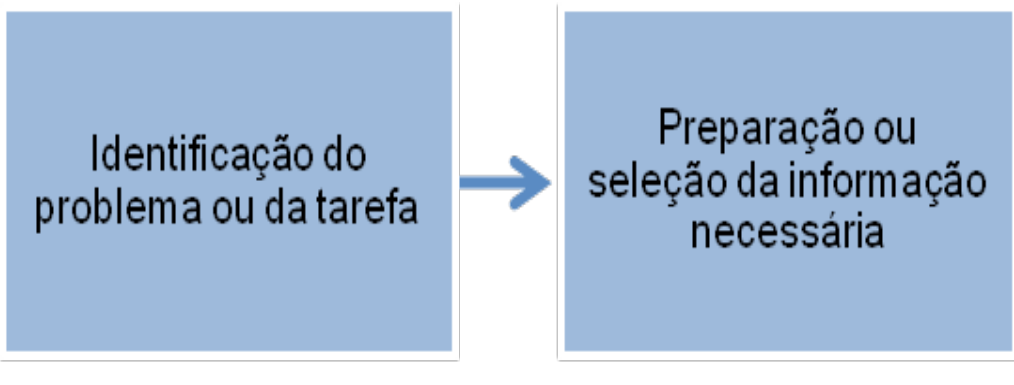

Fase 3

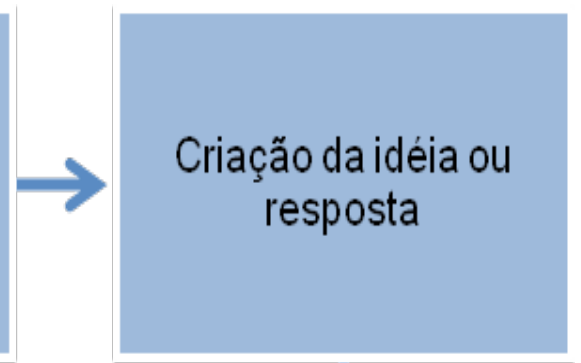

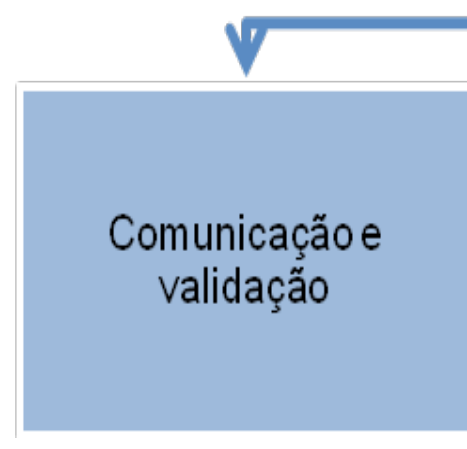

Fase 4

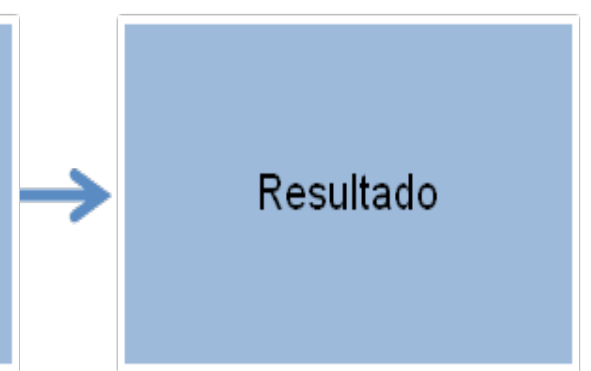

Fase 5

Fonte: Adaptado de Amabile (1989). 
As cinco fases do modelo de Amabile (1989) envolvem a pessoa em um processo no qual ela deverá identificar o problema a ser solucionado. Caso o nível de motivação intrínseca for alto pela atividade, será o suficiente para engajá-la. Na segunda fase, é necessário o desenvolvimento de habilidade de domínio, pois é o momento em que a pessoa busca ou estabelece um conjunto de informações relevantes para solução do problema. Na fase seguinte, cria várias possibilidades de resposta, em que o nível de originalidade do produto ou resposta é determinante, sendo que, nesta fase o uso dos processos criativos relevantes e da motivação intrínseca é de fundamental importância. A quarta fase requer que a pessoa comunique a sua ideia ou produto de alguma forma, para que este seja testado. Dessa maneira, [...] a pessoa faz uso das suas habilidades de domínio para avaliar a extensão em que o produto ou resposta será criativa, útil, correta e de valor para a sociedade de acordo com critérios estabelecidos pelo domínio. (SANTOS, 2010, p.33).

A última fase representa a tomada de decisão no concernente à resposta, com base na avaliação da fase anterior. É necessário ressaltar que, caso a resposta ou produto tenha solucionado o problema com sucesso, o processo é encerrado. Caso contrário, se a resposta ou o produto não tenha solucionado por alguma falha na ação, o processo também finaliza.

Por outro lado, se a resposta for parcial, o processo retorna às fases anteriores. Observase que o objetivo maior deste processo está em adquirir conhecimento e incorporá-lo ao repositório de habilidades de domínio, além de proporcionar experiências prévias com o problema, a fim de produzir respostas mais criativas em momentos posteriores. No caso de resultados parciais ou de insucesso, é necessário que a pessoa se sinta motivada para dar continuidade ao trabalho ou reiniciá-lo. É importante ressaltar, ainda, que as fases não ocorrem, necessariamente, numa sequência lógica (AMABILE, 1983; 1996).

O modelo componencial da criatividade de Amabile demonstra que os componentes intraindividuais são influenciados pelos contextos pessoais, sociais e motivacionais, e que a criatividade é algo que resulta da interação deles, desmistificando a ideia de que a criatividade é apenas uma qualidade das pessoas.

Já o modelo da perspectiva de sistemas de Csikszentmihalyi é um modelo sistêmico no qual a criatividade é compreendida como um ato, ideia ou produto que modifica um domínio ou transforma em outro; ou seja, o conhecimento estruturado de uma área de domínio é compartilhado e alterado, na medida em que é aceito por quem exibe poder de decidir se é ou não criativo. $\mathrm{O}$ autor considera que a criatividade não deve ser estudada de forma isolada do ambiente de trabalho ou estudo, do contexto social e histórico em que as pessoas se encontram. Para Csikszentmihalyi (1996, p.28), uma pessoa criativa é "[...] alguém cujos pensamentos ou ações mudam um domínio, ou estabelecem um novo domínio".

O modelo sistêmico de Csikszentmihalyi propõe que a criatividade pode ser observada na inter-relação de três elementos principais (Figura $3)$. 
Figura 3: Elementos Principais do Modelo Sistêmico.

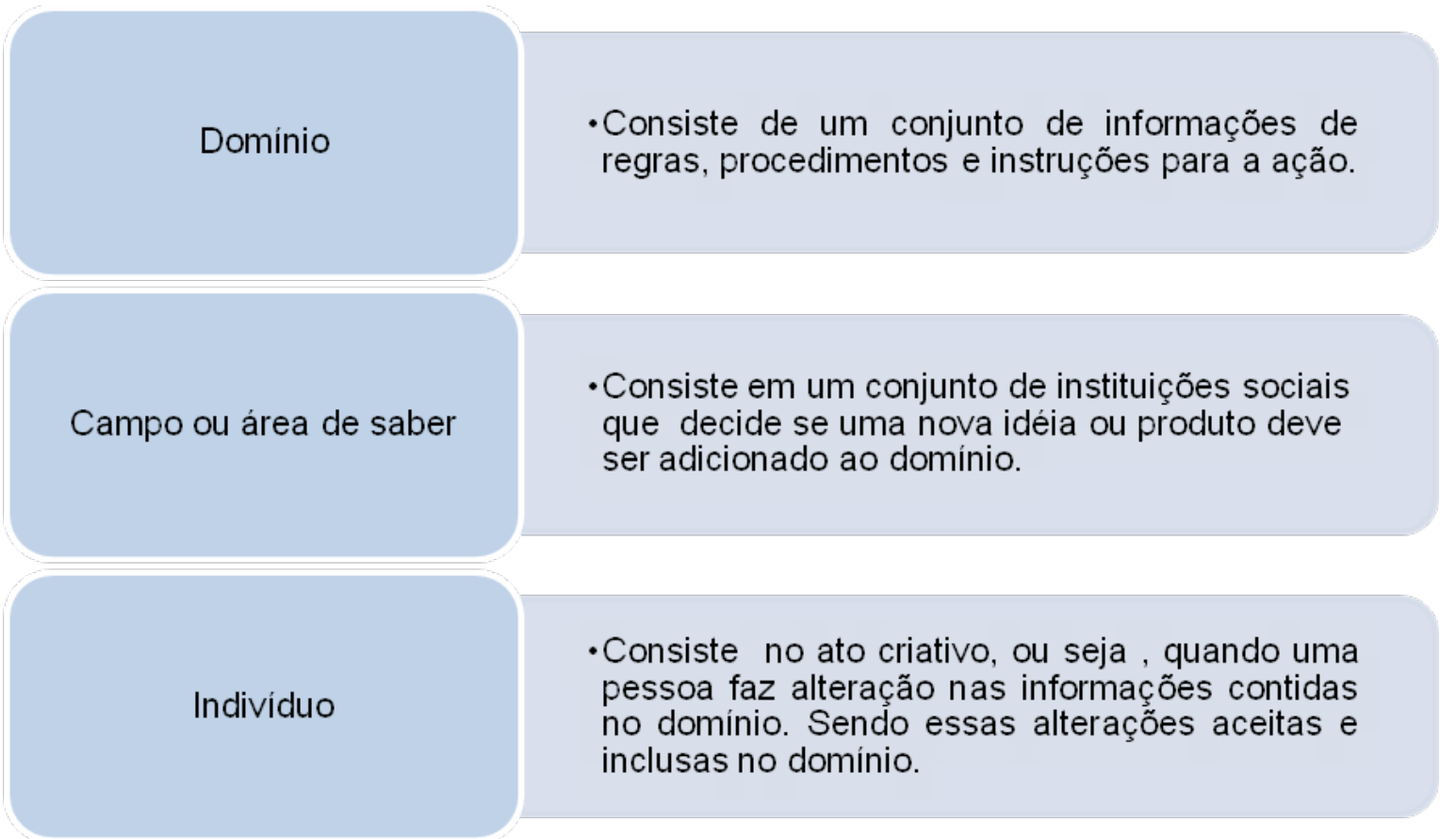

Fonte: Adaptado de Csikszentmihalyi (1996).

Para melhor visualizar a inter-relação dos elementos, busca-se exemplificar. A Ciência da Informação é um domínio, a Biblioteconomia, no âmbito da Ciência da Informação, pode ser considerada um subdomínio. O campo na Ciência da Informação é composto por seus pesquisadores, instituições e as próprias pessoas parte do desenvolvimento deste campo. O último elemento é a criação da pessoa que poderá ser ou não inclusa no campo de domínio. Observase, então, que, neste modelo, a interação dos elementos afeta o todo e as partes do sistema, ou seja, o processo criativo não é apenas o resultado de ações individuais, mas é co-criado por domínios e campo. (ALENCAR; FLEITH, 2003).

$\mathrm{O}$ modelo teórico do investimento em criatividade, inicialmente, se restringia a alguns atributos internos, o que contribuía para o funcionamento criativo, como inteligência, estilo cognitivo e personalidade/motivação (STERNBERG, 1988). Após um período de amadurecimento intelectual, Sternberg e Lubart (1991-1996) consideraram a criatividade como resultado da convergência de seis elementos distintos, porém, inter-relacionados e necessários para a expressão criativa. Esses elementos encontram-se representados e sintetizados no Quadro1.

Quadro1: Elementos resultantes da criatividade.

\begin{tabular}{|c|l|l|}
\hline Inteligência & $\begin{array}{l}\text { Capacidade sintética } \\
\text { Capacidade analítica } \\
\text { Capacidade prático- } \\
\text { contextual }\end{array}$ & $\begin{array}{l}\text { Insight } \\
\text { Co d i f i c a çã o } \\
\text { seletiva; } \\
\text { Comparação }\end{array}$ \\
\hline $\begin{array}{c}\text { Estilos } \\
\text { Intelectuais }\end{array}$ & $\begin{array}{l}\text { Legislativo } \\
\text { Executivo } \\
\text { Judiciário }\end{array}$ \\
\hline Conhecimento & $\begin{array}{l}\text { Formal } \\
\text { Informal }\end{array}$ \\
\hline Personalidade & $\begin{array}{l}\text { Predisposição a correr o riscos } \\
\text { Coragem para expressar novas ideias } \\
\text { Confiança em si mesmo } \\
\text { Perseverança diante de obstáculos } \\
\text { Tolerância à ambiguidade } \\
\text { Um certo grau de autoestima }\end{array}$ \\
\hline Contexto & $\begin{array}{l}\text { Estímulo } \\
\text { Avaliação } \\
\text { Encorajamento e apoio } \\
\text { Interna } \\
\text { Externa }\end{array}$ \\
\hline
\end{tabular}

Fonte: Adaptado de Sternberg e Lubart (1991-1996). 
Para que haja melhor entendimento dos seis elementos e a integração entre si e seus componentes, será detalhado cada um dos elementos. Em relação à inteligência, existem três habilidades cognitivistas importantes a serem consideradas: a capacidade sintética de reformular ou ver o problema sob um novo ângulo; a capacidade analítica de reconhecer, dentre as próprias ideias, a mais apropriada para solucionar o problema, e a capacidade práticocontextual, que é a habilidade de persuadir outras pessoas sobre o valor de sua ideia. Ressaltase que a confluência destas três habilidades é importante, uma vez que se considera que a habilidade analítica utilizada na ausência das duas outras aplicaria o pensamento crítico e não criativo. O primeiro pensamento é um processo utilizado para determinar a veracidade, a exatidão e o valor das suposições que sustentam as ideias de cada qual, e o segundo pensamento é empregado para gerar e ensejar ideias que são originais, úteis e valiosas.

No que tange a habilidade sintética, na ausência das outras duas, produziria novas ideias, porém, não necessariamente, ideias promissoras ou aplicáveis, uma vez que a solução mais criativa resulta da capacidade de se redefinir um problema, sendo identificados três tipos de insight. Esses insights são: a codificação seletiva - ocorre quando a pessoa reconhece e seleciona a informação que, aparentemente, não é óbvia para a solução do problema; comparação seletiva - envolve o pensamento analógico, a utilização de informação gerada no passado e utilizada para resolver problemas do presente e, por fim, a combinação seletiva - ocorre quando se reúnem informações cuja conexão não é óbvia.

Os estilos mentais são divididos em: legislativo, presente na pessoa que gosta de formular problemas e criar regras e maneiras de ver as coisas, sendo este estilo importante para a criatividade; executivo está presente naquele que gosta de implementar ideias, e o terceiro e último estilo é o judiciário, presente na pessoa que gosta de emitir julgamentos, avaliar pessoas, tarefas e regras (ALENCAR; FLEITH, 2003).

O terceiro elemento é o conhecimento, ou seja, o domínio sobre a área de conhecimento em que se atua. Esse domínio sobre a área poderá ser constituído por dois tipos de conhecimento: o formal, que se adquire por meio de instrumentos formais (escola, livro, palestras etc.) ou, informal, recebido por meio de dedicação e observação de uma determinada área. Ambos, porém, são considerados importantíssimos para a criatividade.

Quanto à personalidade, alguns traços contribuem para a expressão da criatividade, destacando-se: predisposição a correr riscos, coragem para expressar novas ideias, confiança em si mesmo, perseverança diante de obstáculos, tolerância à ambiguidade e certo grau de autoestima, embora nem todos estejam necessariamente presentes. Para Alencar e Fleith $(2003$, p.3), “[...] a tolerância à ambiguidade é vista como condição sine qua non para a performance criativa em distintas áreas. Isto por que as ideias necessitam de tempo para amadurecer." É importante ressaltar que esses traços de personalidade são relativamente estáveis e influenciados pelo contexto ambiental.

Além disso, não se pode esquecer de que estes atributos estão parcialmente sob o controle pessoal, podendo a pessoa desenvolvê-los se o quiser.

A motivação interna refere-se à força impulsionadora do desempenho da criatividade, proveniente do interior do sujeito, e se encontra centrada na atividade. Por outro lado a motivação externa provém do meio exterior, mediante incentivos monetários ou reconhecimentos. Ambos os tipos de motivação frequentemente interagem, combinando-se para fortalecer $\mathrm{o}$ potencial criativo.

O último elemento do modelo é o contexto ambiental, que torna claro, que para haver criatividade, o ambiente deve facilitar o potencial criativo. Sabe-se, contudo, que o potencial criativo é influenciado por outros fatores como, por exemplo, "o nível do potencial criativo da pessoa e da área em que a pessoa criativa expressa." (ALENCAR; FLEITH, 2003, p.4). O ambiente que facilita a expressão criativa interage com várias pessoas e situações, de uma forma complexa. Segundo Sternberg e Lubart (1991-1996), o contexto ambiental afeta a produção criativa de três maneiras distintas: o grau em que favorece a geração de ideias; extensão em que encoraja e dá o suporte necessário ao desenvolvimento das ideias criativas, possibilitando a geração de produtos tangíveis e a avaliação que é feita do produto criativo.

As três abordagens aqui apontadas enfatizam que o ato criativo é influenciado pelos 
fatores sociais, culturais e históricos na produção e avaliação do trabalho criativo, embora a pessoa tenha um papel ativo no processo criativo.

\section{INTER-RELAÇÃO ENTRE CRIATIVIDADE E COMPETÊNCIA EM INFORMAÇÃO}

O desenvolvimento consciente da criatividade não se dá de uma hora para outra, exige importantes transformações nas atitudes e hábitos dos indivíduos. Ao se estabelecer, contudo, um diálogo entre a experiência e a indagação, permite encontrar as condições para realmente se efetuar o ato de criar.

Antes de se terminar as reflexões aqui expostas sobre criatividade, é necessário remeterse ao termo inovação, pois a criatividade se concretiza no contexto social por via das ações inovadoras. Tais ações significam introduzir mudanças num objeto de forma planejada, visando a gerar sua melhoria.

$\mathrm{O}$ conceito de inovação, desde a perspectiva pedagógica, depende do conceito de educação que oriente o procedimento inovador. Deve-se considerar que, em determinado entendimento de educação, as ações e procedimentos que a concretizam recebem influência. Dessa maneira, uma determinada mudança introduzida nas práticas pedagógicas desenvolvidas em um dado contexto deve, em primeiro lugar, ser submetida ao crivo dos fins que a motivaram para ser considerada significativa (FEIRE, 1992).

O desafio da inovação no âmbito social está muito relacionado a modificações das práticas pedagógicas e suas inter-relações com as necessidades reais da sociedade.

Observa-se que o desenvolvimento da criatividade, delineada neste artigo, está inter-relacionado com os aspectos arrolados à capacidade de construir conhecimento, mediado por experiências; o ato criativo é fruto da capacidade de mobilizar um conjunto de informação, além de ser um fenômeno que requer domínio de determinada área do conhecimento, ou seja, solicita da pessoa competências essenciais a uma ação criativa.

Acredita-se que a CoInfo, poderá agregar mais valor no desenvolvimento da criatividade permitindo aos indivíduos um acesso e uso da informação de forma produtiva e inteligente, constituindo conhecimento aplicável à sua realidade social. Desse modo, daremos ênfase as inter-relações entre a criatividade e os padrões e indicadores Information Literacy Competency Standards for Higher Education da Association of College and Research Libraries (ACRL, 2000), que servirão como instrumentos de intercessão das inter-relações constituídas pelas leituras realizadas durante a pesquisa, além de ser um elemento norteador para o estabelecimento das relações entre a criatividade e a CoInfo.

Verifica-se na literatura que as abordagens de aprendizagem por competência, criatividade e da competência em informação, devem ter em vista a aprendizagem, como algo desenvolvido e adquirido ao longo da vida, e não somente um fator genético da pessoa. Outra característica inter-relacionada entre esses três elementos é a resolução de problemas reais mediante aplicação do conhecimento adquirido.

A concepção do desenvolvimento destes elementos deve abarcar os âmbitos social, interpessoal, intrapessoal e profissional, e consiste em detectar as semelhanças do que está sendo colocado com as experiências, permitindo mobilizar um funcionamento cognitivo de transferência de informação para soluções criativas e significativas.

Competência, criatividade e CoInfo passam a ser uma variável contínua, que pode ser estimulada ou inibida. A ampliação desses elementos, entretanto, requer maneiras de encadear e articular as ações de ensino-aprendizagem ao longo do desenvolvimento humano, ou seja, as ações devem ser acrescidas de modo funcional e significativo, atribuindo sentido ao que se aprende. Isso decorre e vai além da disciplina, dedicação, esforço consciente e trabalho prolongado de um processo cognitivo relacionado ao procedimento psicológico que envolve conhecer, compreender e perceber, entre outros elementos.

Com origem nos padrões e indicadores da ACRL (2000), observou-se a possibilidade de inter-relacionar os elementos da aprendizagem por competência e da criatividade aos padrões da CoInfo. A inter-relação a ser expressa será das primícias citadas anteriormente sobre criatividade os padrões e indicadores da CoInfo.

A criatividade ocupa um papel estratégico na busca pela inter-relação com a CoInfo, pois ela abrange os campos estético, inventivo e de 
pensamento científico. As características do pensamento criativo, por sua vez, envolvem a abundância de ideias sobre um mesmo assunto; a capacidade de mostrar distintas categorias de respostas não comuns; capacidade de detalhar uma ideia; e decisão, como também demonstram traços criativos como autonomia, flexibilidade pessoal à abertura de experiência, autoconfiança, iniciativa, persistência e sensibilidade emocional.

Ao se estabelecer a inter-relação do modelo componencial da criatividade de Amabile (1996) com os padrões e indicadores da CoInfo (Figura 4), deve-se observar que a criatividade e a CoInfo não representam elementos de caráter unicamente genético e sim de uma ação contínua e amplo conhecimento da área e que se age.

Figura 4: Inter-relação do modelo componencial da criatividade com os padrões da CoInfo

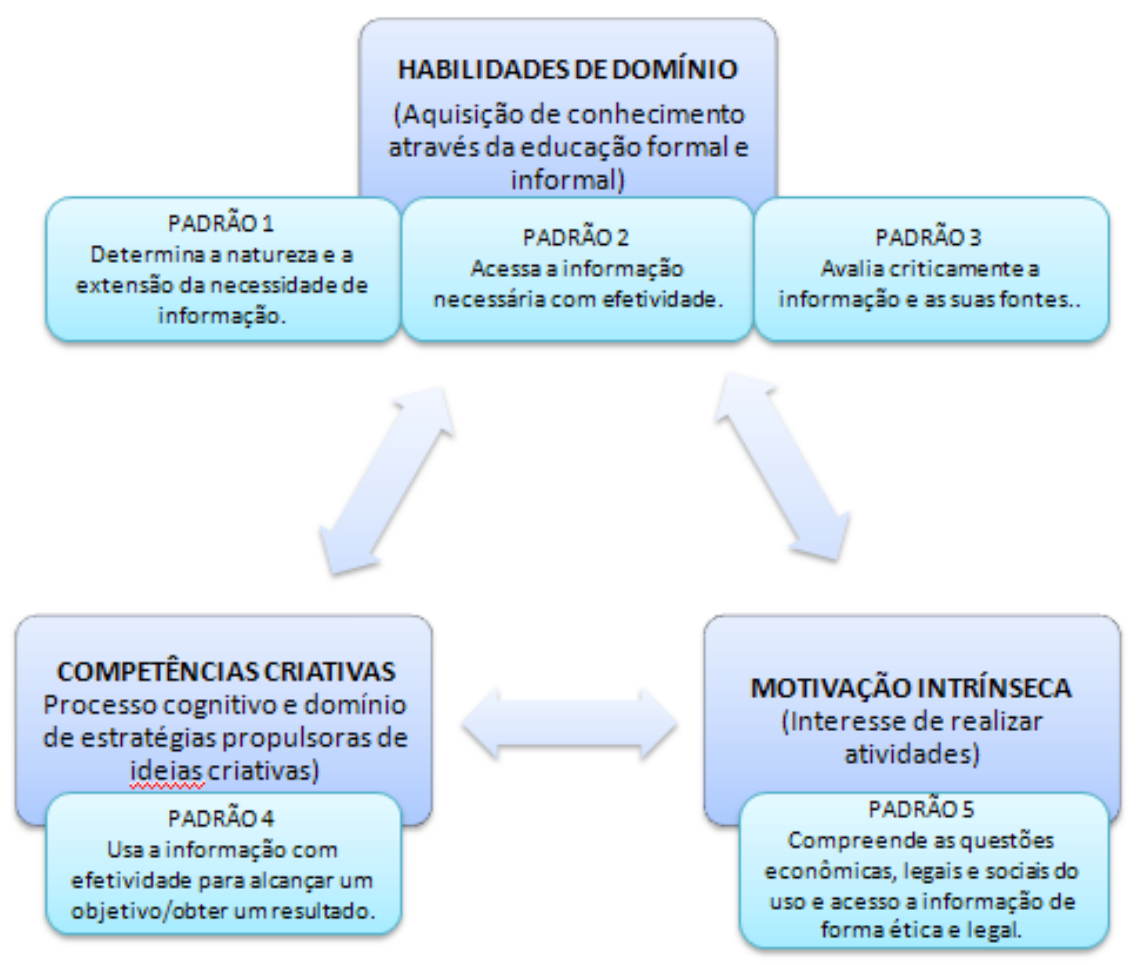

Fonte: Crédito da autora.

A inter-relação dos padrões 1, 2 e 3 com as habilidades de domínio consistem na capacidade desenvolvida por meio da educação formal e informal em decide a natureza e a extensão da informação de que necessita, além de acessá-la efetivamente para então avaliá-la criticamente, articulando-a e comparando-a para agregar ou produzir outra informação suscitando novo conhecimento. As competências criativas estão relacionadas ao processo cognitivo em usar a informação para formular novas ideias, propiciando uma inter-relação com o padrão 4 , ou seja, ao formular novas ideias, a pessoa é capaz de sintetizar a informação acessada com efetividade para desenvolver conceitos inovadores, no intuito de formar uma ideia e de comunicar os resultados essenciais da ideação. Por outro lado motivação intrínseca está relacionada à capacidade de se realizar uma ação de forma ética e também legal, independentemente dos incentivos externos, tendo sua inter-relação com o padrão 5 no qual a pessoa é capaz de compreender as questões legais, sociais e econômicas, em associação ao uso e acesso da informação de forma ética.

As cinco fases propostas por Amabile (1996), estabelecem afinidade com os padrões e indicadores da Competência em Informação, (Figura 5). 
Figura 5: Inter-relação das fases do desenvolvimento da criatividade com os padrões da Competência em Informação.

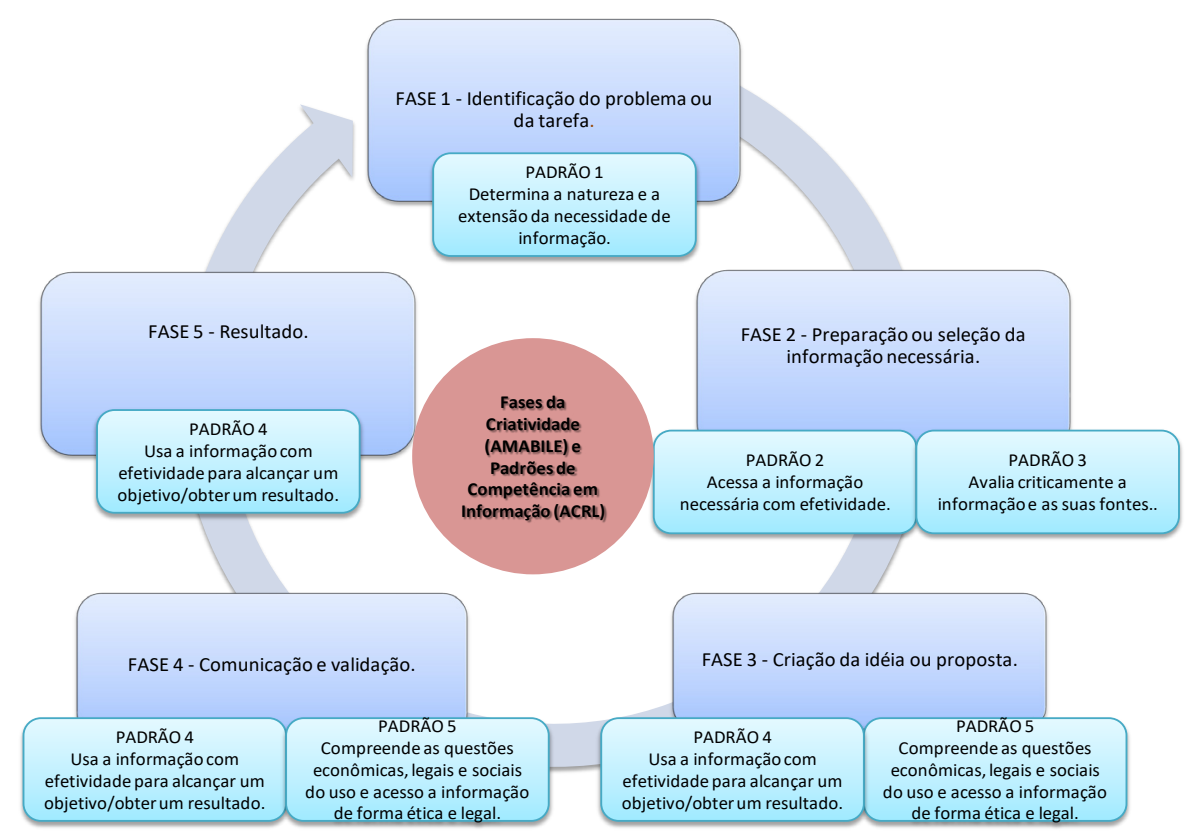

Fonte: Crédito da autora.

$\mathrm{Na}$ inter-relação da fase 1 de desenvolvimento da criatividade com o padrão 1 da Competência em Informação, verifica-se que a motivação intrínseca da pessoa opera de forma positiva no seu engajamento na identificação do problema/ tarefa a executar, buscando reconhecer a necessidade e determinando a natureza e extensão da informação que poderá trazer a solução a esse problema ou tarefa que está precisando desempenhar. Além disso, certamente, também, estará envolvida com os indicadores que consolidam esse padrão, no sentido de que: identificará uma variedade de tipos e formatos de fontes de informação potenciais e levará em consideração os custos e benefícios da aquisição da informação necessária. A fase 2 estabelece uma inter-relação com os padrões 2 e 3, no tocante à capacidade de acesso efetivo e a avaliação crítica da informação. Durante a fase 2, é necessário optar por um método apropriado à recuperação da informação nas bases de dados, permitindo, assim, constituir estratégias efetivas para buscar a informação independentemente de seu formato, o resultado informacional dessas ações, por conseguinte, suscitará uma avaliação das informações, articulando-as e comparando-as a um conhecimento prévio e portanto assimilando um novo contexto informacional. A inter-relação das fases 3, 4 e 5 de desenvolvimento da criatividade com o padrão 4 está relacionada à capacidade de uso efetivo da informação sintetizada, de forma que seja alcançado um objetivo preestabelecido, tendo implicações nele e gerando um resultado original, para que haja uma comunicação ética e também legal, com intuito de validar a ação. O padrão 5 tem inter-relação com as fases 3 e 4, pois, para que haja a criação e, posteriormente, a efetivação da ação com validação de uma determinada área do conhecimento, é necessário que, ao decorrer do processos das fases 3 e 4 de desenvolvimento da criatividade, haja acesso e uso dos recursos informacionais, compreendendo as questões econômicas, legais e sociais da 
informação para que a promoção seja ética e legal gerando benefícios para todos. Ressalta-se que as fases não ocorrem num encadeamento lógico, pois cada uma deverá estabelecer e buscar seu processo de acordo com o nível de competência que já incorporou.

Por outro lado, o modelo da perspectiva de sistema de Csikszentmihalyi (1996) situa a criatividade como elemento modificador de um domínio que possibilita o estabelecimento de outro domínio. O modelo estabelece o domínio, campo do saber e pessoa como elementos principais que constituem uma interação deles e que afeta o todo e as partes do sistema. Uma inter-relação desse modelo (Figura 6) com os padrões da CoInfo (ACRL, 2000).

Figura 6: Inter-relação do modelo sistêmico da criatividade com os padrões da Competência em Informação.

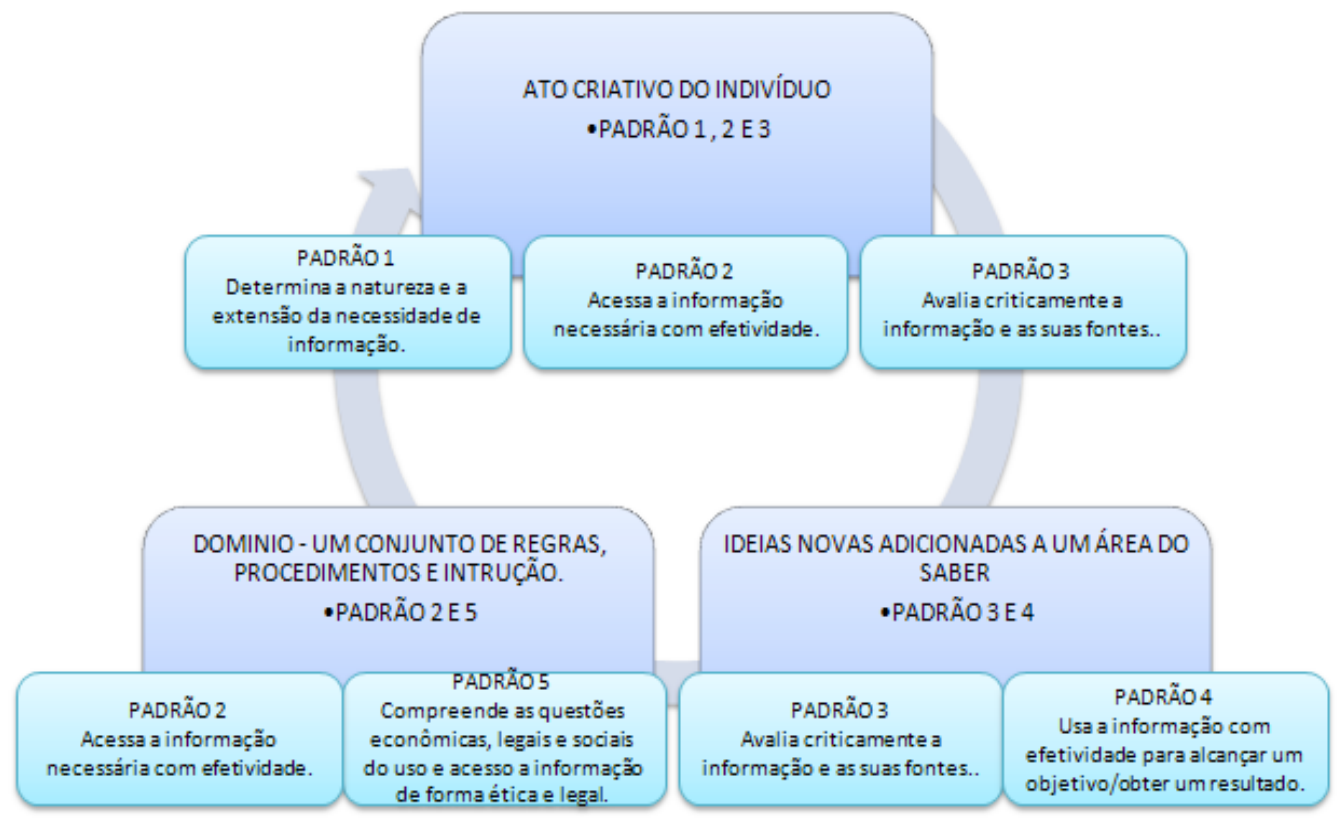

Fonte: Crédito da autora.

As informações contidas na Figura 6 partem da premissa de que os três elementos do modelo sistêmico têm interação, afetando o todo, ou seja, o resultado final é decorrente de uma ação mútua dos elementos. $O$ ato criativo possui inter-relação com os padrões 1 , 2 e 3 da Competência em Informação, pois, na criação, é necessário que haja delimitação da natureza e extensão da informação necessária, considerando os custos e benefícios para que tenha um acesso efetivo na recuperação da informação, visando a uma comparação entre a informação adquirida com o conhecimento prévio, determinando características inovadoras para área do saber. Os padrões 3 e 4 estão inter- relacionados às ideias novas, pois, ao articular a informação adquirida, determinando um valor agregado a ela, é sinal de que durante esse processo houve avaliação crítica da informação capaz de alcançar um objetivo e obter um resultado ao domínio. O domínio, por sua vez, estabelece inter-relação com o padrão 5, ao verificar as alterações efetivadas através da informação será capaz de compreender as questões econômicas, legais e sociais do uso da informação. Os fatores do modelo sistêmico são componentes que interferem diretamente no desenvolvimento dos conjuntos de aproximação dos padrões de Competência em Informação. Portanto, pode-se afirmar que, 
sendo assim, as ações de aprendizagem podem ser planejadas para desenvolver atitude de pesquisa, de autonomia crítica, a busca criativa, e outras palavras, ações que estabeleçam a cultura da pesquisa construtiva, direcionada ao desenvolvimento das competências. (FARIAS; BELLUZZO, 20I3, p.I07).

Destaca-se, ainda, a ideia de que os projetos educacionais e pedagógicos deverão privilegiar o desenvolvimento da criatividade e da Competência em Informação para que as pessoas sejam capazes de agir de forma significativa na sociedade (FARIAS; BELLUZZO, 2013). Os instrumentos a serem planejados poderão ter os princípios da aprendizagem significativa, que implica organizar e integrar os conceitos e proposições da Competência em Informação e suas inter-relações com a aprendizagem por competência e criatividade, integrando-os a uma dada disciplina, programando o conteúdo de forma lógica e conectado a um encadeamento de ações que desenvolva os padrões da Competência em Informação mediante exercícios práticos. Tornando visível o encadeamento das ideias-âncoras existente na disciplina com os padrões e indicadores da Competência em Informação, consolidando o estudo e assegurando a continuidade do processo ensino-aprendizagem.

Constatou-se, que as inter-relações suscitadas ensejam afinidade entre criatividade e a CoInfo, estabelecendo elementos a serem privilegiados no âmbito do desenvolvimento humano, tanto nas competências disciplinares quanto nas competências transversais.

\section{CONSIDERAÇÕES FINAIS}

Foram delineados os diversos conceitos e teorias para o entendimento da temática criatividade e CoInfo. Com amparo numa visão integradora entre essas temáticas, foi possível verificar a possibilidade da inter-relação entre os elementos bases das duas temáticas.

Os resultados foram devidamente descritos, interpretados e descritos e, agora, são sistematizados na forma de conclusões. Vale ressaltar, contudo, que por se conduzir como um estudo de natureza progressiva, não houve a intenção precípua de encerrar possíveis discussões a respeito das temáticas envolvidas, sendo que se procurou apenas elucidar uma posição e sua defesa quanto ao entendimento sobre a importância de se contribuir com subsídios à consolidação da criatividade somada a CoInfo como área de importância no desenvolvimento social no contexto brasileiro. Assim, espera-se que este artigo possa trazer importante colaboração para mais aprofundamentos e reflexões sobre esse tema.

Evidencia-se que o processo de criatividade aliada a CoInfo na contemporaneidade não está relacionado apenas à dimensão subjetiva dos sujeitos envolvidos, indo além das habilidades cognitivas. É necessário refletir, entretanto, questionar e redefinir os papéis dos sujeitos na sociedade com intuito de atender o foco da realidade demanda pela sociedade.

Os protagonistas, o indivíduo precisa refletir e agir de forma colaborativa para as mudanças emergentes da sociedade contemporânea ocorra de forma sustentável.

Buscou-se averiguar a importância do fenômeno da criatividade aliada a CoInfo. Ao contrário do que se imaginava, a criatividade pode ser desenvolvida e aprimorada mediante práticas e por meio da formação, mas necessita disciplina, dedicação, esforço consciente, trabalho contínuo e conhecimento amplo de uma área do saber.

Os modelos teóricos atuais da criatividade que foram analisados: Teresa Amabile (Modelo Componencial da Criatividade, de Mihaly Csikszentmihalyi (Perspectiva de Sistemas) e de Robert Sternberg (Teoria do Investimento em Criatividade) são considerados padrões de abordagens confluentes, pois visam ao estudo da criatividade como um fenômeno complexo multifacetado, sujeito a influências ambientais ou motivacionais. São elementos fundamentais e inter-relacionados com os padrões e indicadores da Competência em Informação.

As inter-relações estabelecidas e apresentadas tornam-se subsídios para uma prática sustentável com base no desenvolvimento de indivíduos socialmente responsáveis e conscientes de sua atitude perante as demandas da sociedade. E, por esse motivo, o indivíduo passa a ter um novo papel no atual contexto social.

A inter-relação da criatividade com CoInfo é determinante para o desenvolvimento social, cultural e econômico de um país. Trabalhar com essa interrelação requer uma mobilização de conhecimentos procedimentais, atitudinais e conceituais.

Espera-se que este artigo, embora representando um passo inicial na oferta de base teórica, possa incentivar a realização de novas perspectivas tendo como base o desenvolvimento da CoInfo. 
Artigo recebido em 09/02/20 I 8 e aceito para publicação em 22/04/20I 8

\section{MUTUAL RELATIONSHIP BETWEEN ELEMENTS OF CREATIVITY AND INFORMATION LITERACY}

ABSTRACT The article presents, through a bibliographical survey and systematic observation, a reflection on the theoretical aspects that cover the concepts related to the phenomenon of creativity and its interrelationship with the development of information competence (Colnfo). It highlights the relations established between the theoretical cognitive models on the creativity of Teresa Amabile (Component of Creativity, Mihaly Csikszentmihalyi (Systems Perspective) and Robert Sternberg (Theory of Investment in Creativity) and the standards and indicators of the Information Literacy Competency Standards for the study of creativity as a complex multifaceted phenomenon that is subject to environmental influences, and is considered to be a confluent model of creativity, The interrelations established and presented are the basis for a sustainable practice based on the development of individuals who are socially responsible and aware of their attitude towards the in of the society.

Keywords: $\quad$ Creativity. Information Literacy.

\section{REFERÊNCIAS}

ALENCAR, E. M. L. S.; FLEITH, D. S. Contribuições teóricas recentes ao estudo da criatividade. Psicologia. Teoria e Pesquisa, Brasília, v. 19, n.1, p. 1-8, 2003.

. Psicologia da criatividade. Porto Alegre: Artes Medicas Sul, 1986. v. 1. 85p

AMABILE, T. A. The social psychology of creativity. New York: Springer. 1983.

. Growing up creative. Buffalo, New York: The creative education Foundation Press. 1989.

Creativity in context. Boulder, CO: Westview Press. 1996.

ASSOCIATION OF COLLEGE AND RESEARCH LIBRARIES - ACRL. Information literacy competency for higher education. Chicago: ALA, 2000. Disponível em: <http://www. ala.org/ala/mgrps/divs/acrl/standards / informationliteracycompetencystan dards.cfm>. Acesso em: 06 ago. 2013.

Information literacy competency standards for higher education. Chicago,
ACRL/ALA, 2000. Disponível em: <http:// www.ala.org/ala/acrl/acristandards/standards. pdf>. Acesso em: 07 set. 2013.

CSIKSZENTMIHALYI, M. Creativity. New York: HarperCollins. 1996.

FARIAS, G. B. ; BELLUZZO, R. C. B. . Reflexões conceituais sobre conhecimento e competência: ensaio para o desenvolvimento de ações de ensino-aprendizagem. In: Lídia Eugenia Cavalcante; Virgínia Bentes Pinto; Silvana Aparecida Borsetti Gregório Vidotti. (Org.). Ciência da informação e contemporaneidade: tessituras e olhares. Fortaleza: Edições UFC, 2013, v. 1, p. 89-116.

FREIRE, P. Pedagogia da esperança: um reencontro com a pedagogia do oprimido. Rio de Janeiro: Paz e Terra, 1992.

PEREIRA, M. Criatividade: um conceito irredutível à investigação psicológica? Revista Portuguesa de Pedagogia, n.2, v.1, 1996, p.23-41.

SANTO, M. C. Criatividade e autoconceito: um estudo exploratório com crianças do $5^{\circ}$ ano de escolaridade. 2010. 109 f. Dissertação (Mestrado em Psicologia da Educação) - Universidade Lusófona de Humanidades e Tecnologias, Portugal, 2010. 
LUHART, T. I.In investment theory

STERNBERG, R. J. A three-facet modelof creativity. In: contemporary . The nature of creativity psychological perspectives. Cambridge: Cambridge University Press. 1988. p. 125-147 of creativity and its development. Human Development, v. 34, p.1-31. 1991.

. Investing in creativity. American Psychologist, v.51, p.677-688. 1996. 